\title{
INFLUENCE OF FEEDING SYSTEM IN INJECTION MOULDING FOR LOWER WASHER OF A BEARING
}

\author{
Vikas B J ${ }^{1}$, Chandra Kumar $\mathbf{R}^{\mathbf{2}}$ \\ ${ }^{1}$ M. Tech. Student, ${ }^{2}$ Asst. Professor, Department of Mechanical Engineering, $R$ V College of Engineering, Karnataka, \\ India, vikas5440@gmail.com., chandrakumarr@rvce.edu.in
}

\begin{abstract}
Optimisation of cycle time, avoid scrap and manual interface plays a vital role in manufacturing of plastic parts to improve the productivity of the process and at the time it should not affect the quality of the final product. This paper describes the influence of gate location and size through a repeated number of analyses which is carried out by plastic flow advisor software to reduce fill time, scrap and automatic degating. The process parameters like fill time, shrinkage, weld lines, pressure drop, and air traps are analysed by simulation in successive trials. Experimental verification has been done with new optimised gate location with designed mould in injection moulding machine. The results showed an improvement in fill time from $1.64 \mathrm{sec}$ to $1.2 \mathrm{sec}$ with increase in injection pressure by $15 \mathrm{MPa}$. Shrinkage and air traps were reduced minimising trouble shooting defeats.
\end{abstract}

Index Terms: Plastic Injection mould, Mould Flow Plastic Advisor, Feeding system, Submarine gate, Nylon 6/6 30\% GF

\section{INTRODUCTION}

The injection moulding process involves the injection of a polymer melt into a mould, where the polymer melt, cools and solidifies to form a plastic product. The process comprises filling, packing, and cooling phases. The typical process cycle time in injection moulding machine varies from several seconds to tens of seconds depending on the part weight, part thickness, material properties and the machine settings specific to a given process. Process control of injection moulding has a direct impact on the final part quality and the economics of the process. In the injection moulding processes, gate location is very important design parameter with is in the relation with polymer capability, part shape and dimension, mould structure and mould condition, the selection of gate location influences the manner in which plastic flows in to the mould cavity. In order to set the processing parameters, conventional trial and error method is followed which is many times inadequate and unpractical for complex parts. The placement of a gate in an injection mould is one of the most important variables in mould design and the quality of the product is greatly affected by the gate location. Thus the objective of this paper is to design the feeding system that ensures the better part quality to design and manufacturing the injection mould for lower washer of a bearing.

\section{PART DETAILS}

The bearing material of Nylon 6/6 GF30 which has an excellent balance of properties which make it an ideal material for metal replacement in applications such as automotive parts, industrial valves, railway tie insulators, and other industry uses whose design requirements include high strength, toughness, and weight reduction. The part is designed for four impression injection moulds and volume of the component is $32.12 \mathrm{~cm} 3$, with the density of $1.35 \mathrm{gm} / \mathrm{cc}$ and the shrinkage of the part is $0.6 \%$. The CAD model of the part is shown in the Fig1.
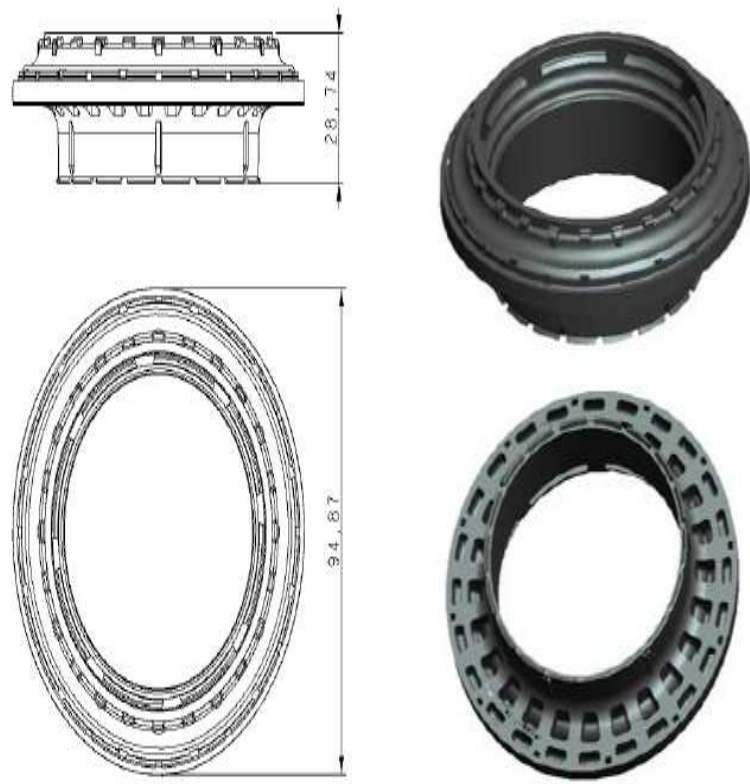

Fig 1 CAD Model of Lower washer 


\section{GATE LOCATION}

Since the part is designed for multi-impression mould and circular profile part allows us to design only submarine gate for feeding. A submarine gate is used in two-plate mould construction. An angled, tapered tunnel is machined from the end of the runner to the cavity, just below the parting line. A submarine gate is often located into the side of an ejector pin on the non-visible side of the part. To de-gate, the tunnel requires a good taper and must be free to bend. Typical gate sizes $0.8 \mathrm{~mm}$ to $1.5 \mathrm{~mm}$, for glass reinforced materials sizes could be larger shown in Fig 2.

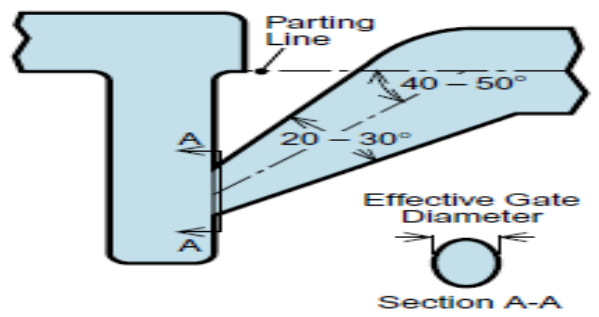

Fig 2 Submarine Gate

Flow simulation in plastic advisor for component suggests the best gate location for the selected material properties. The simulation rates the model areas for their suitability for injection location where the worst position is classified as least suitability for an injection location in red colour and the best position is classified as the most suitable in blue colour. The input for plastic advisor software is given in the Table 1 and the gate location examines these five aspects of the part.

1. Process ability.

2. Minimum Pressure.

3. Geometric Resistance (Over packing).

4. Thickness.

5. Flow resistance areas

Table 1 Input Details for plastic Advisor

\begin{tabular}{|l|l|}
\hline Material & PA6,6 GF 30\% \\
\hline Pressure & $180 \mathrm{Mpa}$ \\
\hline Density & $1.35 \mathrm{gm} . / \mathrm{cc}$ \\
\hline Melt Temperature & $280^{\circ} \mathrm{C}$ \\
\hline Manufacturer & G E Plastics \\
\hline Mould Temp & $80^{\circ} \mathrm{C}$ \\
\hline
\end{tabular}

Since it is a multi-impression mould and circular component only submarine gate can be used for feeding. A submarine gate is used in two-plate mould construction. An angled, tapered tunnel is machined from the end of the runner to the cavity, just below the parting line. A sub-gate is often located into the side of an ejector pin on the non-visible side of the part when appearance is important. To de-gate, the tunnel requires a good taper and must be free to bend. Typical gate sizes $0.8 \mathrm{~mm}$ to $1.5 \mathrm{~mm}$, for glass reinforced materials sizes could be larger. Cold sprue with submarine gate was used for analysis. Part is simulated for four cavities where single occurrence will be considered for Simulation. The gate is located on the highly recommended area (blue colour) shown in Fig 3. The gates are given across the surface of the washer, where it is the only possibility because other recommended area damages the part dimensions and others are impossible to manufacture the feeding system.

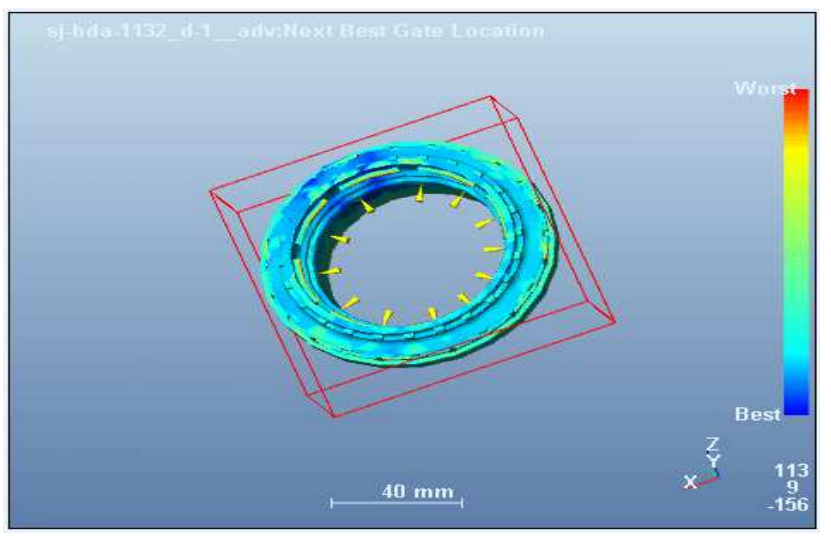

Fig 3 Best Gate location selection

\section{SHRINKAGE}

Sink marks are developed in the part in the region of thick features such as ribs or bosses in the adjacent wall of the part. The presence of such a feature creates an effectively thicker region that cools more slowly than neighbouring regions. Shrinkage occurs because of longer hold time, low pressure, and short cooling time or with sprue less hot runners. Fig 4 suggests that the part shrinkage will be within $0.02 \mathrm{~mm}$ to 0.14 $\mathrm{mm}$ and this factor is incorporated in designing the core and cavity block.

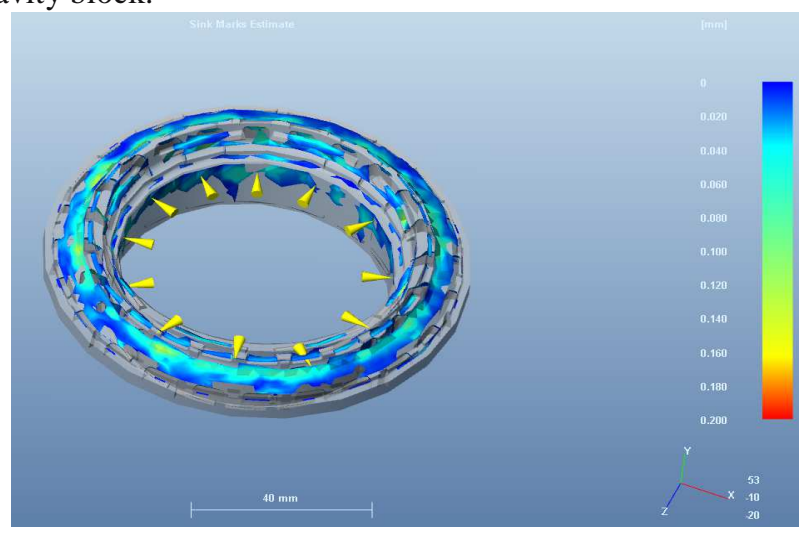

Fig 4 Part Shrinkage 


\section{MOULD FLOW RESULTS}

The mould flow Simulation is done repeatedly and best three trials are show and the possible is selected for manufacturing based on fill time and air traps.

\subsection{First Trail}

Feeding system is designed and simulated with 8 Gates, $2 \mathrm{~mm}$ diameter gate size and runner width of $6 \mathrm{~mm}$ in first trail shown in Fig 5, where the part fills in $1.64 \mathrm{sec}$ with pressure of $14.66 \mathrm{Mpa}$ where air traps and sink marks are maximum, which leads defects in the component and more over ejection is quite difficult as $2 \mathrm{~mm}$ gates tears the component surface because of shear force caused by Pins.

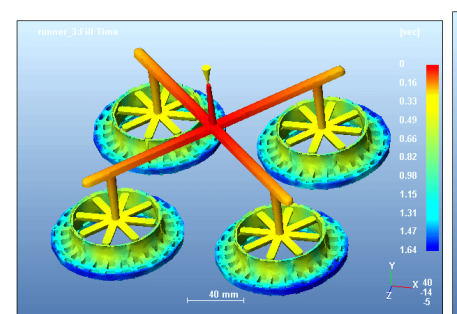

(a)

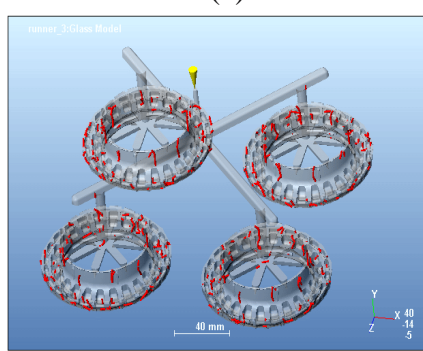

(c)

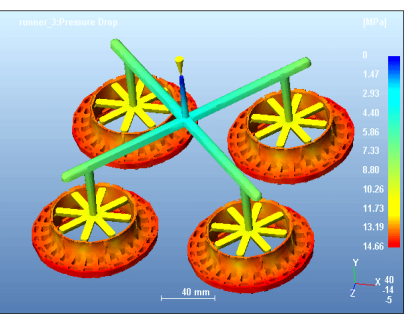

(b)

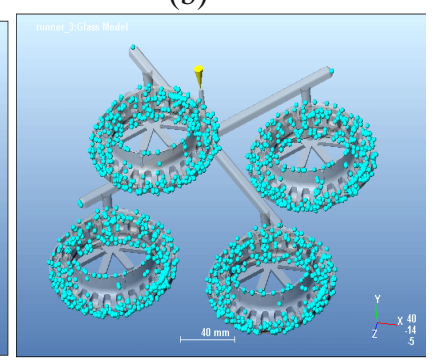

(d)
Fig 5 Flow Simulation with 8 Gates and $2 \mathrm{~mm}$ dia. for a) Fill Time b) Pressure Drop c) Weld lines d) Air Traps

\subsection{Second Trail}

Since the results obtained in first trail are not satisfactory, feeding system is redesigned and simulated with 12 Gates, 1.6 $\mathrm{mm}$ diameter and runner width of $6 \mathrm{~mm}$ shown in Fig 6 , where the part fills in $1.26 \mathrm{sec}$ with pressure of $25.5 \mathrm{Mpa}$ where air traps are less, but weld line are marginally high. Since the results were better than the previous trail, there is a scope for further optimising the gate sizes for less tear on the component surface for better quality of the component.

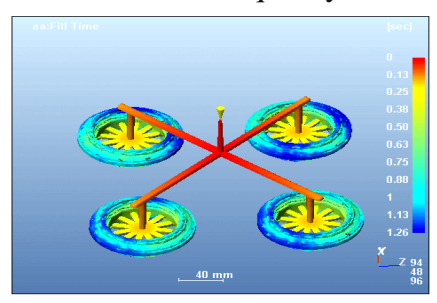

(a)

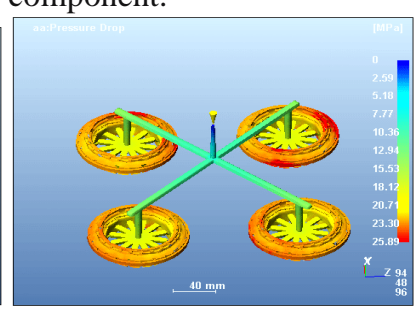

(b)

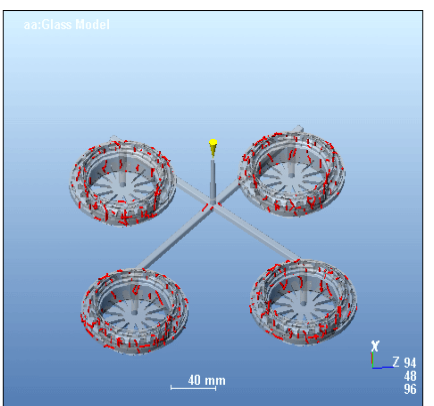

(c)

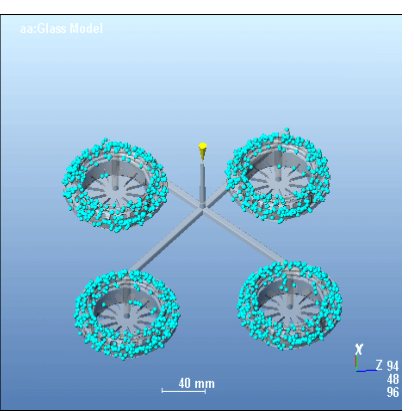

(d)
Fig 6 Flow Simulation with 12 Gates and $1.6 \mathrm{~mm}$ dia. for a) Fill Time b) Pressure Drop c) Weld lines d) Air Traps

\subsection{Third Trail}

Results obtained from second trail can be further optimized by changing only the gate size and simulated with 12 Gates, 1.2 $\mathrm{mm}$ diameter gate and runner width $3 \mathrm{~mm}$, shown in Fig 7 , where the part fills in $1.2 \mathrm{sec}$ with pressure of $29.46 \mathrm{Mpa}$, even though the pressure is relatively high compared to previous, it is manageable and since the gate diameter is $1.2 \mathrm{~mm}$ the part is automatically ejected as the cross section of gate is minimum with very less tear on the component surface. Even though the air traps are more, it can be minimised with air vents in cavity insert during manufacturing.

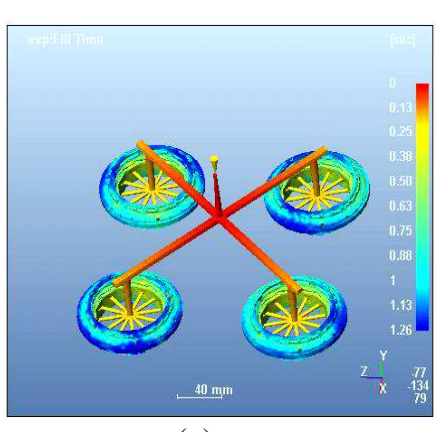

(a)

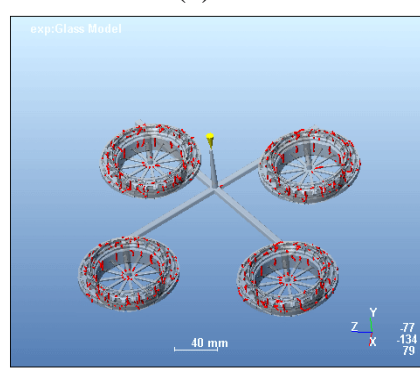

(c)

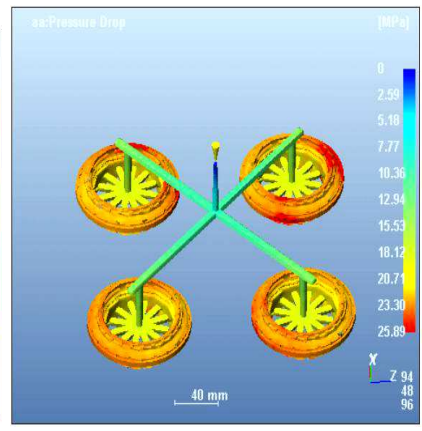

(b)

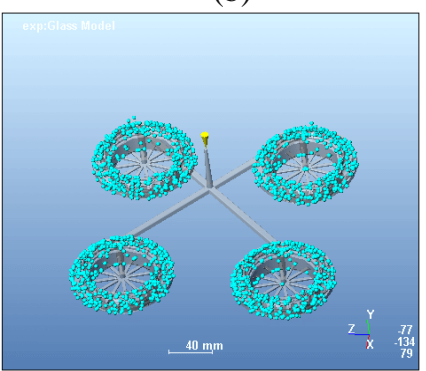

(d)
Fig 7 Flow Simulation with 12 Gates and $1.2 \mathrm{~mm}$ dia. for a) Fill Time b) Pressure Drop c) Weld lines d) Air Traps 


\section{CONCLUSIONS}

Analysing the above three results with a comparative study, the analysis for optimum gate and runner location was discussed, defects like air traps and weld lines were minimized in the flow simulation. Gate is designed in best location for easy manufacturing and defects less component where automatic degating is possible. From the three trails in the Table 2, even though pressure increases, it is well within the safe range and fill time comes down which will increase the production rate. Flow simulation for different gate size and locations were analysed flaws like weld lines and air traps were minimised to produce defect less component Air traps can be minimized by providing air vents in core and cavity inserts, weld lines can be controlled by monitoring injection pressure, barrel speed and maintaining the mould temperature. Trial three is considered for design since fill time, air traps are minimum and ejection is easy and automatic.

Table 2 Mould flow Results Comparison

\begin{tabular}{|l|l|l|l|}
\hline & 1 st Trail & 2nd Trail & 3rd Trail \\
\hline Fill time & $1.64 \mathrm{sec}$ & $1.26 \mathrm{Sec}$ & $1.20 \mathrm{Sec}$ \\
\hline Pressure & $14.66 \mathrm{Mpa}$ & $25.5 \mathrm{Mpa}$ & $29.46 \mathrm{Mpa}$ \\
\hline $\begin{array}{l}\text { Temp } \\
\text { flow }\end{array}$ & $295 \mathrm{C}$ & $295 \mathrm{C}$ & $295 \mathrm{C}$ \\
\hline Air Traps & More & More & Acceptable \\
\hline Weld lines & More & Minimum & More \\
\hline Ejection & $\begin{array}{l}\text { Difficult } \\
\text { and } \\
\text { Complex }\end{array}$ & $\begin{array}{l}\text { Difficult } \\
\text { and } \\
\text { Complex }\end{array}$ & $\begin{array}{l}\text { Easy and } \\
\text { Automatic }\end{array}$ \\
\hline
\end{tabular}

\section{ACKNOWLEDGMENTS}

I am very thankful to the PG staff and faculty of R V College of Engineering and Spectrum Tool Engineering Pvt. Ltd Bangalore, for providing me an opportunity to work on this paper as part of my academic work. I am deeply indebted and highly obliged to Prof. Chandra Kumar R, Dept. of Mechanical Engineering, my guide for his valuable suggestions and support in the completion of the paper successfully.

\section{REFERENCES}

[1] S.R. Pattnaik, D.B. Karunaka, P.K. Jha, "Application of Computer Simulation for Finding Optimum Gate Location in Plastic Injection Moulding Process", International Journal of Advanced Engineering
Research and Studies, Vol No.1, pp 159-161, March 2012.

[2] Cheng-Hsien, Wu. Yu-Jen Huang,"The influence of cavity deformation on the shrinkage and warpage of an injection moulded part", International Journal of Manufacturing Technology, Vol. No. 6, pp 1144-1154, March 2007.

[3] HongSeok Park and Xuan-Phuong Dang, "Design and Simulation Based Optimization of Cooling Channels for Plastic Injection Mould", International Journal of Precision Engineering and Manufacturing, Vol. No. 6, pp. 879-890, March 2012.

[4] Cheng-Hsien, Wu. Yu-Jen Huang,"The influence of cavity deformation on the shrinkage and warpage of an injection moulded part", International Journal of Manufacturing Technology, Vol. No. 6, pp 1144-1154, March 2007.

[5] Ko-Ta Chiang and Fu-Ping Chang, "Analysis of shrinkage and warpage in an injection moulded part with a thin shell feature using the response surface.", The International Journal of Advanced Manufacturing Technology, Vol. No.35, pp. 468-479, December 2007.

[6] R.G.W. Pye, "An Introduction, and Design Manual for the thermoplastics Industry," 4th Edition, East West Press Pvt. Ltd, New Delhi, 2000.

[7] Dominick. V. Rosato, Donald. V. Rosato and Marlene. G. Rosato, "Injection Moulding Handbook," 3rd Edition, Kluwer academic publishers, 2000.

\section{BIOGRAPHIES}

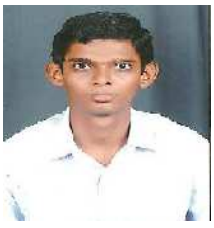

Vikas B $\mathrm{J}$ is persuing $\mathrm{M}$. tech in Tool Engineering from $\mathrm{R} V$ college of Engineering, Bangalore. He has completed B.E in Mechanical Engineering from Sapthagiri College of Engineering, Bangalore. His areas of interest are in design of Injection mould, press tools and Fixture.

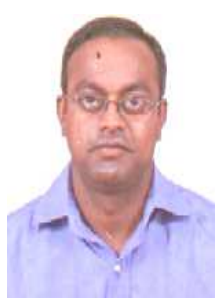

Chandra kumar $\mathrm{R}$ is currently working as Assistant Professor at dept. of Mechanical Engineering, R V College of Engineering, Bangalore. $\mathrm{He}$ has completed $\mathrm{BE}$ (Mechanical) and M.Tech (Product Design \& Manufacturing). Currently he is pursuing $\mathrm{Ph} . \mathrm{D}$ in Mechanical Engineering. He has published papers in the area of Mechanical Sciences. He has teaching experience for both UG and PG programs \& industrial experience. He has guided several UG and $P G$ projects 